University of Wollongong

Research Online

Faculty of Engineering - Papers (Archive)

Faculty of Engineering and Information

Sciences

$1-1-2012$

\title{
Rapid microwave-assisted synthesis of Mn304-graphene nanocomposite and its lithium storage properties
}

Li Li

University of Wollongong, li@uow.edu.au

Zaiping Guo

University of Wollongong, zguo@uow.edu.au

Aijun Du

University of Queensland

Hua-Kun Liu

University of Wollongong, hua@uow.edu.au

Follow this and additional works at: https://ro.uow.edu.au/engpapers

Part of the Engineering Commons

https://ro.uow.edu.au/engpapers/5220

\section{Recommended Citation}

Li, Li; Guo, Zaiping; Du, Aijun; and Liu, Hua-Kun: Rapid microwave-assisted synthesis of Mn304-graphene nanocomposite and its lithium storage properties 2012, 3600-3605.

https://ro.uow.edu.au/engpapers/5220

Research Online is the open access institutional repository for the University of Wollongong. For further information contact the UOW Library: research-pubs@uow.edu.au 


\title{
Journal of

\section{Rapid microwave-assisted synthesis of $\mathrm{Mn}_{3} \mathrm{O}_{4}-$ graphene nanocomposite and its lithium storage properties $\uparrow$}

\author{
$\mathrm{Li} \mathrm{Li},{ }^{a}$ Zaiping Guo, ${ }^{* a b}$ Aijun Du*c and Huakun Liu ${ }^{a}$ \\ Received 8th October 2011, Accepted 9th December 2011 \\ DOI: $10.1039 / \mathrm{c} 2 \mathrm{jm} 15075 \mathrm{a}$
}

\begin{abstract}
A nanocomposite of $\mathrm{Mn}_{3} \mathrm{O}_{4}$ wrapped in graphene sheets (GSs) was successfully synthesized via a facile, effective, energy-saving, and scalable microwave hydrothermal technique. The morphology and microstructures of the fabricated GS- $\mathrm{Mn}_{3} \mathrm{O}_{4}$ nanocomposite were characterized using various techniques. The results indicate that the particle size of the $\mathrm{Mn}_{3} \mathrm{O}_{4}$ particles in the nanocomposite markedly decreased to nearly $20 \mathrm{~nm}$, significantly smaller than that for the bare $\mathrm{Mn}_{3} \mathrm{O}_{4}$. Electrochemical measurements demonstrated a high specific capacity of more than $900 \mathrm{~mA} \mathrm{~h} \mathrm{~g}^{-1}$ at $40 \mathrm{~mA} \mathrm{~g}^{-1}$, and excellent cycling stability with no capacity decay can be observed up to 50 cycles. All of these properties are also interpreted by experimental studies and theoretical calculations.
\end{abstract}

\section{Introduction}

Manganese oxide, due to its low toxicity and natural abundance, as well as its low price, has been a key topic among the transitionmetal oxides. Besides its potential applications in diverse areas, including catalysis ${ }^{1-3}$ and electrochromic applications, ${ }^{4 a}$ its suitability for rechargeable lithium ion batteries (LIBs), ${ }^{4 b}$ as well as high power supercapacitors, ${ }^{5}$ has also attracted worldwide interest in the energy storage field. The theoretical specific capacity of $\mathrm{Mn}_{3} \mathrm{O}_{4}$ is around $937 \mathrm{~mA} \mathrm{~h} \mathrm{~g}^{-1}$, which is nearly three times higher than that of graphite $\left(\sim 372 \mathrm{~mA} \mathrm{~h} \mathrm{~g}^{-1}\right)$. Nevertheless, only a few papers have reported $\mathrm{Mn}_{3} \mathrm{O}_{4}$ in lithium batteries so far, as it is virtually an insulator with very low electrical conductivity $\left(\sim 10^{-7}\right.$ to $\left.10^{-8} \mathrm{~S} \mathrm{~cm}^{-1}\right)$, which limits its capacity to around $400 \mathrm{~mA} \mathrm{~h} \mathrm{~g}{ }^{-1}$, even with the addition of cobalt. ${ }^{6}$ Graphene, as a rising star in materials science with its well-defined two-dimensional honeycomb-like network of carbon atoms, has aroused explosive interest in the nanoscience and nanotechnology fields owing to its outstanding thermal stability, ${ }^{7}$ superior electronic conductivity $\left(\sim 2000 \mathrm{~S} \mathrm{~cm}{ }^{-1}\right),{ }^{8}$ large theoretical specific surface area $\left(\sim 2630 \mathrm{~m}^{2} \mathrm{~g}^{-1}\right)$, and high intrinsic mobility $\left(200000 \mathrm{~cm}^{2} \mathrm{~V}^{-1} \mathrm{~s}^{-1}\right),{ }^{9,10}$ as well as its remarkable structural flexibility. ${ }^{11,12}$ Therefore, in light of its fascinating merits and low

anstitute for Superconducting and Electronics Materials, University of Wollongong, Wollongong, 2500, Australia.E-mail: zguo@uow.edu.au; Fax: +61 242215225

${ }^{b}$ School of Mechanical, Materials, and Mechatronic Engineering, University of Wollongong, Wollongong, 2500, Australia

${ }^{c}$ Centre for Computational Molecular Science, Australian Institute for Bioengineering and Nanotechnology and School of Chemical Engineering, University of Queensland, Queensland, 4072, Australia. E-mail: a.du@ uq.edu.qu

$\dagger$ Electronic supplementary information (ESI) available: TGA curves, $\mathrm{CV}$ curves, computational details and Nyquist plots. See DOI: 10.1039/c2jm15075a costs, it has been suggested that graphene sheet (GS) could be an ideal substrate for growth of functional nanomaterials ${ }^{13-15}$ to render them electrochemically active and electrically conductive. With this in mind, numerous graphene-based inorganic nanocomposites with metal, ${ }^{16-19}$ metal oxides, ${ }^{20-24}$ and sulfide ${ }^{14}$ have been successfully synthesized and show enhanced properties of these host materials.

Herein, we have employed a novel, facile, and fast one-pot microwave hydrothermal technique to obtain well-organized $\mathrm{Mn}_{3} \mathrm{O}_{4}$ encapsulated in graphene sheets $\left(\mathrm{GS}-\mathrm{Mn}_{3} \mathrm{O}_{4}\right)$. Compared with the traditional hydrothermal method, the microwave hydrothermal method can increase the kinetics of crystallization by causing rapid nucleation and growth, which can dramatically reduce the reaction time from 10 hours ${ }^{25}$ or even several days via the conventional hydrothermal method down to $30 \mathrm{~min}$, as reported here, and therefore it can save a large amount of energy. Additionally, the most important point to be noted is that, compared with the conventional hydrothermal method, the application of microwaves in the heating process offers a great possibility for large-scale batch reactions. Furthermore, through the microwave hydrothermal method, various multifunctional nanomaterials with intriguing morphologies, such as nanospheres, nanowires, and nanoporous networks, can be produced effectively and efficiently. ${ }^{26-28}$

Through this rapid and robust in situ approach, the microwave hydrothermal technique, a hierarchical nanocomposite of $\mathrm{Mn}_{3} \mathrm{O}_{4}$ embedded in graphene sheets $\left(\mathrm{GS}-\mathrm{Mn}_{3} \mathrm{O}_{4}\right)$ was synthesized directly from graphite oxide (GO) and manganese acetate in the presence of anhydrous hydrazine. The reduction of GO and the loading of $\mathrm{Mn}_{3} \mathrm{O}_{4}$ nanoparticles on the graphene sheets occurred simultaneously, which can avoid the introduction of additional molecular cross-linkers to bridge the nanoparticles and the graphene matrix. Therefore, the graphene sheets in the composite can not only efficiently buffer the volume change of 
$\mathrm{Mn}_{3} \mathrm{O}_{4}$ nanoparticles during charging and discharging processes but also preserve the high electrical conductivity of the whole electrode. As a consequence, the fabricated $\mathrm{GS}-\mathrm{Mn}_{3} \mathrm{O}_{4}$ hybrid material possesses high reversible capacity, good cycle life, and high rate capability as anode material for lithium ion batteries, and hence could be considered as a candidate electrode material for high-performance energy storage devices.

\section{Experimental section}

\subsection{Synthesis of the $\mathrm{GS}-\mathrm{Mn}_{3} \mathrm{O}_{4}$ nanocomposite}

Graphite oxide was prepared using a modified Hummers' method as described elsewhere. ${ }^{29}$ In a typical preparation of GS$\mathrm{Mn}_{3} \mathrm{O}_{4}$ nanocomposite, $20 \mathrm{~mL}$ of $\mathrm{GO}\left(0.5 \mathrm{mg} \mathrm{mL}^{-1}\right)$ suspension was diluted to $100 \mathrm{~mL}$ solution by adding $80 \mathrm{~mL}$ deionized water, followed by stirring for $0.5 \mathrm{~h}$. Then, $10 \mathrm{~mL}$ of manganese acetate aqueous solution $(0.2 \mathrm{M})$ was added into the as-prepared GO dispersion under vigorous magnetic stirring for 4 hours, and $2 \mathrm{~mL}$ of $\mathrm{NaOH}$ aqueous solution (2 M) was added dropwise to the above mixture, followed by stirring overnight. Subsequently, $0.2 \mathrm{~mL}$ hydrazine anhydrous was added to the above solution with stirring for $0.5 \mathrm{~h}$, and then the solution was diluted by addition of $100 \mathrm{~mL}$ deionized water. Finally, $20 \mathrm{~mL}$ of the resultant brown solution was transferred to a Teflon-lined autoclave and then was irradiated by microwaves for $30 \mathrm{~min}$ at $150{ }^{\circ} \mathrm{C}$ at a fast heating rate. Please note that the temperature we used is lower and the process is much faster than that reported recently. ${ }^{25}$ After the reaction, the precipitate was collected with a centrifuge and rinsed with deionized water and ethanol three times, respectively. Afterwards, the obtained powders were dried at $60{ }^{\circ} \mathrm{C}$ overnight in a vacuum oven. For comparison, bare $\mathrm{Mn}_{3} \mathrm{O}_{4}$ nanoparticles were also prepared by the same experimental procedures but without adding graphite oxide. By using this method, it was estimated from thermogravimetric analysis (TGA) that the amount of graphene in the GS- $\mathrm{Mn}_{3} \mathrm{O}_{4}$ nanocomposite was about $18.8 \mathrm{wt} \%$, as shown in Fig. S1 in the ESI $\dagger$.

\subsection{Materials characterization}

The phase structures and molecules of the as-prepared products were characterized by MMA GBC X-ray diffraction with $\mathrm{Cu} \mathrm{K} \alpha$ radiation and Raman spectroscopy (Jobin Yvon HR800). The morphology and size of the as-obtained products were investigated using a field-emission scanning electron microscope (FESEM; JEOL-7500, $2 \mathrm{keV}$ ) and a transmission electron microscope (TEM, JEOL 2011, $200 \mathrm{keV}$ ). Thermogravimetric analysis was conducted on a TA 2000 Thermoanalyzer. The working electrodes were prepared by mixing the as-prepared samples, carbon black (Super P, MMM, Belgium), and poly (vinyl difluoride) (PVDF) in a weight ratio of $8: 1: 1$. The resultant slurry was pasted on $\mathrm{Cu}$ foil and dried in a vacuum oven at $80{ }^{\circ} \mathrm{C}$ for $8 \mathrm{~h}$. The electrochemical measurements were carried out in CR2032 coin cells with Li foil as the counter electrode and $1 \mathrm{M} \mathrm{LiPF}_{6}$ in $1: 1$ ethylene carbonate (EC) and dimethyl carbonate (DMC) as the electrolyte. Cyclic voltammograms were collected on a VMP-3 electrochemical workstation at a scan rate of $0.1 \mathrm{mV} \mathrm{s}^{-1}$. The discharge and charge measurements were conducted on a Land CT2001A battery tester.

\section{Results and discussion}

Fig. 1 presents the X-ray diffraction (XRD) patterns of graphene, graphite oxide (GO), and bare $\mathrm{Mn}_{3} \mathrm{O}_{4}$ nanoparticles, as well as the as-prepared $\mathrm{GS}-\mathrm{Mn}_{3} \mathrm{O}_{4}$ nanocomposite, respectively. The diffraction peak at $9.7^{\circ}$ is indexed to GO in Fig. 1(b), and the appearance of the (002) diffraction line at $23.4^{\circ}$ for graphene $e^{30}$ in Fig. 1(a) gives evidence that the graphite oxide was reduced to graphene during the microwave hydrothermal process. Meanwhile, it can also be observed that the graphene peaks become broadened after the reduction, which is a typical pattern of amorphous carbon structure, ${ }^{31}$ revealing that the stacking of GS is substantially disordered.

The characteristic peaks, as labelled in Fig. 1(c) and (d), of the crystal structure of $\mathrm{Mn}_{3} \mathrm{O}_{4}$ in both the nanoparticles and the nanocomposite are in good agreement with tetragonal spinel with space group I41/amd (JCPDS card: 24-0734), which also matches well with previous reports in the literature, ${ }^{25}$ and no other impure crystalline phases were observed. The peaks of the GS- $\mathrm{Mn}_{3} \mathrm{O}_{4}$ nanocomposite become broadened compared with those of bare $\mathrm{Mn}_{3} \mathrm{O}_{4}$, indicating that the grain size of the $\mathrm{Mn}_{3} \mathrm{O}_{4}$ nanoparticles is smaller in the presence of the GS encapsulation than for the bare $\mathrm{Mn}_{3} \mathrm{O}_{4}$.

In addition, the presence of both graphene and $\mathrm{Mn}_{3} \mathrm{O}_{4}$ can be confirmed from typical peaks in the Raman spectra (Fig. 2). Raman scattering probes the vibration modes of both crystalline and amorphous materials, providing complementary structural information to X-ray diffraction. Fig. 2 presents the Raman spectra of GO, GS- $\mathrm{Mn}_{3} \mathrm{O}_{4}$ composite, and bare $\mathrm{Mn}_{3} \mathrm{O}_{4}$ nanoparticles. For the $\mathrm{GO}$ and $\mathrm{GS}-\mathrm{Mn}_{3} \mathrm{O}_{4}$ samples, the $\mathrm{G}$ band $\left(1604 \mathrm{~cm}^{-1}\right)$ arises from the zone centre $E_{2 \mathrm{~g}}$ mode, corresponding to ordered $\mathrm{sp}^{2}$ bonded carbon, whereas the $\mathrm{D}$ band $\left(1330 \mathrm{~cm}^{-1}\right)$ is ascribed to edges or disordered layers. The intensity ratio of the $\mathrm{D}$ to the $\mathrm{G}$ band $\left(I_{\mathrm{D}} / I_{\mathrm{G}}\right)$ provides a sensitive measure of the disorder and crystallite size of the graphitic layers. ${ }^{32}$ The intensity ratio (1.08) of $I_{\mathrm{D}} / I_{\mathrm{G}}$ for $\mathrm{GO}$ is lower than that (1.31) of GS$\mathrm{Mn}_{3} \mathrm{O}_{4}$ composite, suggesting that the reduction of exfoliated

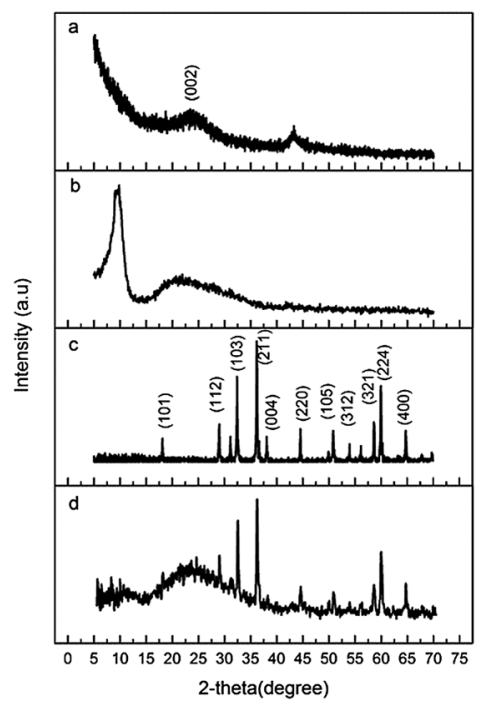

Fig. 1 X-Ray diffraction patterns of (a) graphene, (b) GO, (c) bare $\mathrm{Mn}_{3} \mathrm{O}_{4}$, and (d) as-prepared $\mathrm{GS}-\mathrm{Mn}_{3} \mathrm{O}_{4}$ nanocomposite. 


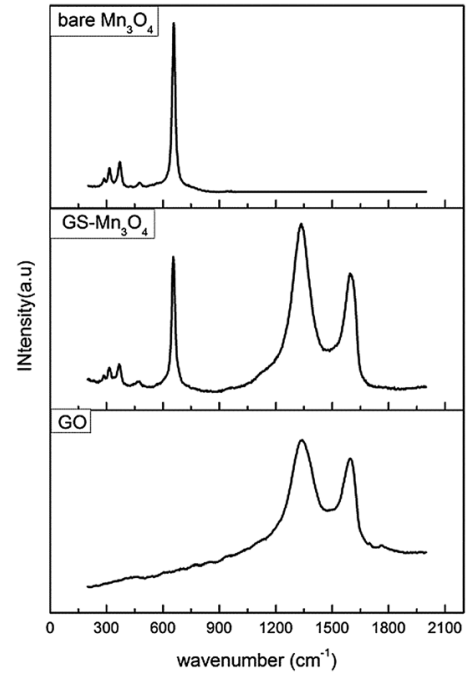

Fig. 2 Raman spectra of bare $\mathrm{Mn}_{3} \mathrm{O}_{4}$ nanoparticles, GS- $\mathrm{Mn}_{3} \mathrm{O}_{4}$ nanocomposite, and GO.

GO leads to smaller and more disordered layers, as well as dramatically decreasing the layer numbers of graphene. ${ }^{33}$ In addition, minor peaks at 317,374 , and $475 \mathrm{~cm}^{-1}$ and a dominant peak at $652 \mathrm{~cm}^{-1}$ in the $\mathrm{GS}-\mathrm{Mn}_{3} \mathrm{O}_{4}$ nanocomposite can be ascribed to crystalline $\mathrm{Mn}_{3} \mathrm{O}_{4},{ }^{34,35}$ which is substantially coincident with the bare $\mathrm{Mn}_{3} \mathrm{O}_{4}$. The Raman spectrum of the GS$\mathrm{Mn}_{3} \mathrm{O}_{4}$ nanocomposite is actually that of a combination of pure graphene and bare $\mathrm{Mn}_{3} \mathrm{O}_{4}$. This implies that $\mathrm{Mn}_{3} \mathrm{O}_{4}$ and GS are all in their own pristine structure, and no reactions have occurred between them during the in situ microwave hydrothermal synthesis process.

To investigate the morphology of the products, field-emission scanning electron microscope (FESEM) images were collected for the bare $\mathrm{Mn}_{3} \mathrm{O}_{4}$ nanoparticles and the $\mathrm{GS}-\mathrm{Mn}_{3} \mathrm{O}_{4}$

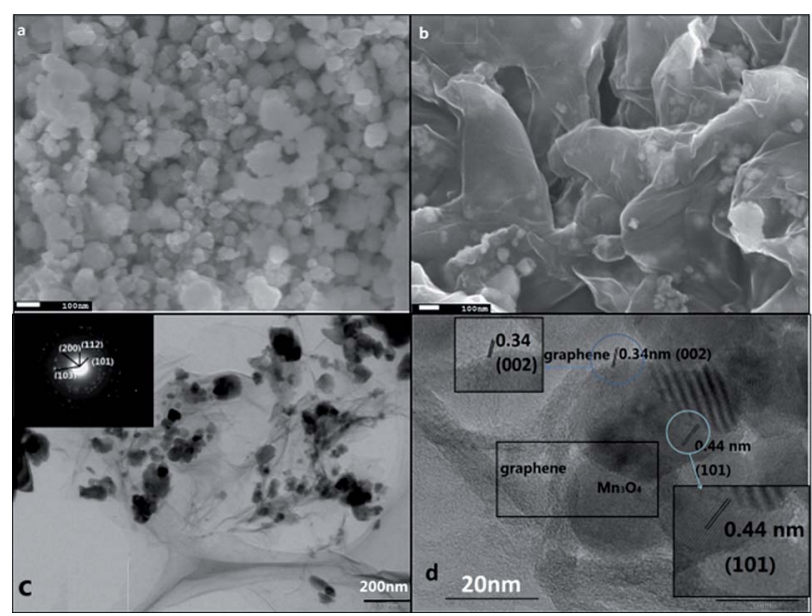

Fig. 3 FESEM images of (a) bare $\mathrm{Mn}_{3} \mathrm{O}_{4}$ nanoparticles and (b) GS$\mathrm{Mn}_{3} \mathrm{O}_{4}$ nanocomposite. TEM images of the GS- $\mathrm{Mn}_{3} \mathrm{O}_{4}$ nanocomposite: (c) large-area image and associated SAED pattern (inset), (d) highresolution TEM image of the $\mathrm{Mn}_{3} \mathrm{O}_{4}$ particle in [101] orientation embedded in graphene sheets and associated selected-area magnified images (insets). nanocomposite, as shown in Fig. 3. The morphology of the bare $\mathrm{Mn}_{3} \mathrm{O}_{4}$ nanoparticles, prepared by the same procedure, but in the absence of GO, is spherical, but the nanoparticles are severely aggregated together, giving rise to a bigger particle size in the range of 40-100 nm (Fig. 3(a)). In comparison, we can observe that the size of the $\mathrm{Mn}_{3} \mathrm{O}_{4}$ nanoparticles is dramatically decreased to around $20 \mathrm{~nm}$ when they are prepared in situ with graphene via the microwave hydrothermal method, as shown in Fig. 3(b). This is because intimate interaction between bare $\mathrm{Mn}_{3} \mathrm{O}_{4}$ particles and hierarchic flexible graphene sheets drastically limits the growth and limits the agglomeration of the crystalline $\mathrm{Mn}_{3} \mathrm{O}_{4}$ particles to some extent, while the $\mathrm{Mn}_{3} \mathrm{O}_{4}$ particles are encapsulated in a matrix of graphene sheets, leading to more effective ionic and electron transport during $\mathrm{Li}^{+}$insertion/de-insertion due to the high conductivity of graphene.

The transmission electron microscope (TEM) images shown in Fig. 3(c) and (d) reveal that the $\mathrm{Mn}_{3} \mathrm{O}_{4}$ nanoparticles were distributed on the surface of the graphene nanosheets in the form of single particles or small particle clusters, and the nature of the $\mathrm{Mn}_{3} \mathrm{O}_{4}$ particles shown in Fig. 3(c) was further confirmed by selected area electron diffraction (SAED) patterns (inset of Fig. 3(c)). These visible diffraction rings can be indexed to the Hausmannite $\mathrm{Mn}_{3} \mathrm{O}_{4}$ phase, which is consistent with the XRD patterns. The high-resolution TEM image (Fig. 3(d)) indicates that there are multiple overlapping layers near the edge of the $\mathrm{Mn}_{3} \mathrm{O}_{4}$ particle, whereas the $d$-spacing of the (002) graphene planes is $0.34 \mathrm{~nm}$, almost equal to the value of pristine graphene. The $\mathrm{Mn}_{3} \mathrm{O}_{4}$ particles were firmly encapsulated by the graphene sheets, and the crystal lattice fringes with $d$-spacing of $0.44 \mathrm{~nm}$ can be assigned to the [101] plane of tetragonal $\mathrm{Mn}_{3} \mathrm{O}_{4}$. Based on the TEM images, it could be further confirmed that there is an intimate interaction between the $\mathrm{Mn}_{3} \mathrm{O}_{4}$ particles and the graphene sheets, and such a combination can enable fast electron transport through the graphene matrix to the $\mathrm{Mn}_{3} \mathrm{O}_{4}$ nanoparticles, guaranteeing efficient electrochemical performance.

In order to highlight the superiority of the $\mathrm{GS}-\mathrm{Mn}_{3} \mathrm{O}_{4}$ nanocomposite as anode material in LIBs, the discharge/charge profiles of the GS- $\mathrm{Mn}_{3} \mathrm{O}_{4}$ nanocomposite and the bare $\mathrm{Mn}_{3} \mathrm{O}_{4}$ nanoparticles at a current density of $40 \mathrm{~mA} \mathrm{~g}^{-1}$ are displayed in Fig. 4(a) and (b), respectively. The cyclic voltammetry (CV) curves of the GS- $\mathrm{Mn}_{3} \mathrm{O}_{4}$ nanocomposite and the bare $\mathrm{Mn}_{3} \mathrm{O}_{4}$ nanoparticles at a scan rate of $0.1 \mathrm{mV} \mathrm{s}^{-1}$ in the potential range from $0.1 \mathrm{~V}$ to $3 \mathrm{~V}$ are shown in Fig. S2 in the ESI $\uparrow$. The general features of the discharge/charge profiles are consistent with those of other transition metal oxides such as $\mathrm{Co}, \mathrm{Fe}$, and $\mathrm{Ni}$ oxide as anode materials in LIBs, but their mechanism of Li reactivity differs from the classical Li insertion/de-insertion or Li-alloying processes, which involves the formation and decomposition of $\mathrm{Li}_{2} \mathrm{O}$ and accompanying reduction and oxidation of metal nanoparticles, as reported by P. Poizot et al. ${ }^{36}$

As can be seen from Fig. 4(a), there is an obvious sloping part in the first discharge cycle from $1.5 \mathrm{~V}$ to $0.38 \mathrm{~V}$, consistent with two broad cathodic peaks at around $0.62 \mathrm{~V}$ and $1.26 \mathrm{~V}$, as shown in Fig. S2(a)†, which can be ascribed to the decomposition of the electrolyte solvent and the formation of the solid electrolyte interphase, as well as initial reduction of $\mathrm{Mn}_{3} \mathrm{O}_{4}$. We can also observe that a well-defined voltage plateau is present at around $0.38 \mathrm{~V}$ in the first discharge cycle as shown in Fig. 4(a), which can be attributed to the further reduction of $\mathrm{MnO}$ to $\mathrm{Mn}$ and the 

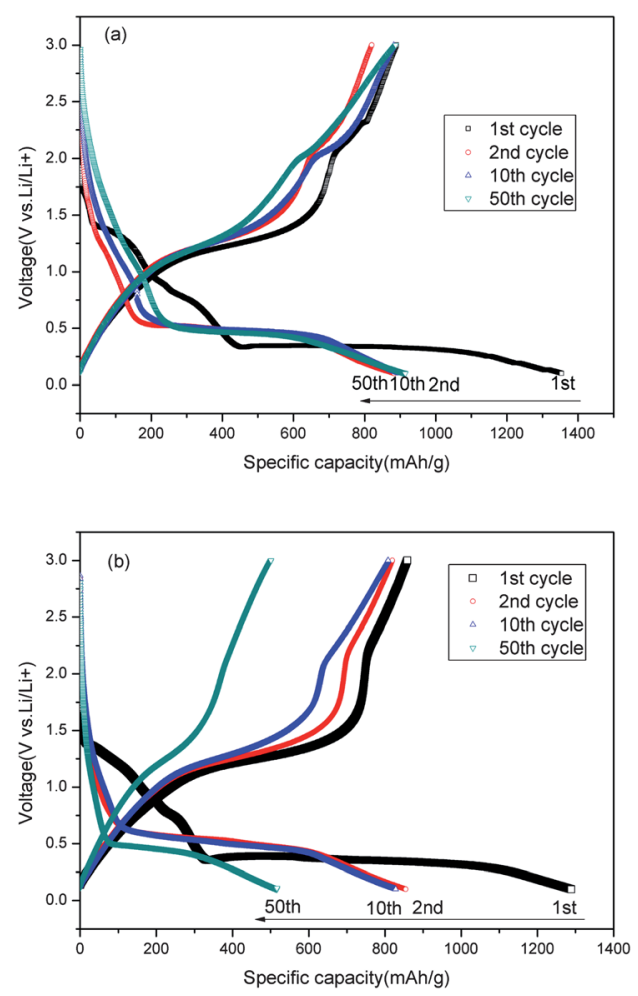

Fig. 4 Galvanostatic charge/discharge profiles for selected cycles of (a) GS- $\mathrm{Mn}_{3} \mathrm{O}_{4}$ nanocomposite, and (b) bare $\mathrm{Mn}_{3} \mathrm{O}_{4}$ nanoparticles at the current density of $40 \mathrm{~mA} \mathrm{~g}^{-1}$ with the potential window from $0.1 \mathrm{~V}$ to $3 \mathrm{~V}$.

formation of amorphous $\mathrm{Li}_{2} \mathrm{O}\left(\mathrm{Mn}_{3} \mathrm{O}_{4}+8 \mathrm{Li}^{+}+8 \mathrm{e}^{-}=3 \mathrm{Mn}+\right.$ $4 \mathrm{Li}_{2} \mathrm{O}$ ), while the capacity extends to approximately $1354 \mathrm{~mA} \mathrm{~h} \mathrm{~g}^{-1}$, slightly higher than the theoretical capacity of $937 \mathrm{~mA} \mathrm{~h} \mathrm{~g}^{-1}$ for the conversion reaction to $\mathrm{Mn}$ and $\mathrm{Li}_{2} \mathrm{O} .^{36,37}$ The higher capacity in the first cycle should be ascribed to the following factors: the discharge capacity in the first cycle is not only contributed by the conversion reaction of $\mathrm{Mn}_{3} \mathrm{O}_{4}$ to $\mathrm{Mn}$ nanoparticles, along with the formation of amorphous $\mathrm{Li}_{2} \mathrm{O}$, but also corresponds to the formation of the solid electrolyte interphase (SEI), which is not included in the theoretical capacity of $\mathrm{Mn}_{3} \mathrm{O}_{4}$. Therefore, the initial discharge capacity is higher than the theoretical value. This is a normal phenomenon in metal oxide anode materials for lithium storage.

At the same time, an apparent broad peak at around $1.34 \mathrm{~V}$ in the first cycle is recorded in the anodic process as shown in Fig. S2(a) $\dagger$, corresponding to the reversible oxidation of $\mathrm{Mn}(0)$ to $\mathrm{MnO}$ during the anodic process. An additional shoulder peak is observed when the material is charged above $2 \mathrm{~V}$; this may correspond to further oxidation of $\mathrm{MnO}$ to $\mathrm{Mn}_{3} \mathrm{O}_{4}$, since it cannot be observed in the charge curve of $\mathrm{MnO}^{37}$ The first charge capacity approaches $890 \mathrm{~mA} \mathrm{~h} \mathrm{~g}^{-1}$ as shown in Fig. 4(a), which is very close to the theoretical capacity $\left(937 \mathrm{~mA} \mathrm{~h} \mathrm{~g}^{-1}\right)$ of a fully reversible conversion reaction. In the subsequent cycles, as shown in Fig. S2(a) $\dagger$, the reduction peaks in the first cycle have disappeared, and a new sharp peak near $0.31 \mathrm{~V}$ appears instead, reflecting the sloping voltage range from $0.6 \mathrm{~V}$ to $0.1 \mathrm{~V}$ in the second cycle of the charge/discharge curve, as shown in Fig. 4(c), which is distinctly higher than for the first discharge, indicating that the lithium insertion reaction in the second cycle has become easier. Fig. 4(b) presents discharge/charge profiles of the bare $\mathrm{Mn}_{3} \mathrm{O}_{4}$ nanoparticles, which are similar to the curve shapes for the GS- $\mathrm{Mn}_{3} \mathrm{O}_{4}$ nanocomposite, except for the relatively poor cycling performance.

The cycling performances of the $\mathrm{GS}-\mathrm{Mn}_{3} \mathrm{O}_{4}$ nanocomposite and the bare $\mathrm{Mn}_{3} \mathrm{O}_{4}$ nanoparticles were measured at a current density of $40 \mathrm{~mA} \mathrm{~g}^{-1}$ in the voltage range from $0.1 \mathrm{~V}$ to $3 \mathrm{~V}$, and the results are shown in Fig. 5(a). We can observe that the second discharge specific capacity of the bare $\mathrm{Mn}_{3} \mathrm{O}_{4}\left(854.6 \mathrm{~mA} \mathrm{~h} \mathrm{~g}^{-1}\right)$ is very close to that of the GS- $\mathrm{Mn}_{3} \mathrm{O}_{4}$ nanocomposite $\left(901.3 \mathrm{~mA} \mathrm{~h} \mathrm{~g}^{-1}\right)$, however, it declines dramatically to only $496 \mathrm{~mA} \mathrm{~h} \mathrm{~g}^{-1}$ after 50 cycles, i.e., $58 \%$ of the capacity in the second cycle. In contrast, the GS- $\mathrm{Mn}_{3} \mathrm{O}_{4}$ nanocomposite maintains a significantly higher reversibility, and it is interesting to note that its reversible capacity even gradually increases to $927 \mathrm{~mA} \mathrm{~h} \mathrm{~g}^{-1}$ at the 20th cycle, which is well-documented in the literature and is attributed to the reversible growth of a polymeric gel-like film resulting from kinetically activated electrolyte degradation..$^{38-40}$ The coulombic efficiency of the GS$\mathrm{Mn}_{3} \mathrm{O}_{4}$ composite after the second cycle remains nearly $100 \%$ up to 50 cycles. We have also compared the rate performance of the GS$\mathrm{Mn}_{3} \mathrm{O}_{4}$ nanocomposite with that of the bare $\mathrm{Mn}_{3} \mathrm{O}_{4}$ at different current densities of $40,100,200,500,1000$, and $2000 \mathrm{~mA} \mathrm{~g}^{-1}$, shown in Fig. 5(b). At $1000 \mathrm{~mA} \mathrm{~g}^{-1}$, the reversible capacity of the GS$\mathrm{Mn}_{3} \mathrm{O}_{4}$ nanocomposite reaches over $400 \mathrm{~mA} \mathrm{~h} \mathrm{~g}{ }^{-1}$, while the capacity of the bare $\mathrm{Mn}_{3} \mathrm{O}_{4}$ is less than $250 \mathrm{~mA} \mathrm{~h} \mathrm{~g}^{-1}$. Remarkably, when the current density is again reduced back to $40 \mathrm{~mA} \mathrm{~g}^{-1}$, the stable capacity of the GS- $\mathrm{Mn}_{3} \mathrm{O}_{4}$ nanocomposite can be almost resumed, and the discharge specific capacity is even slightly
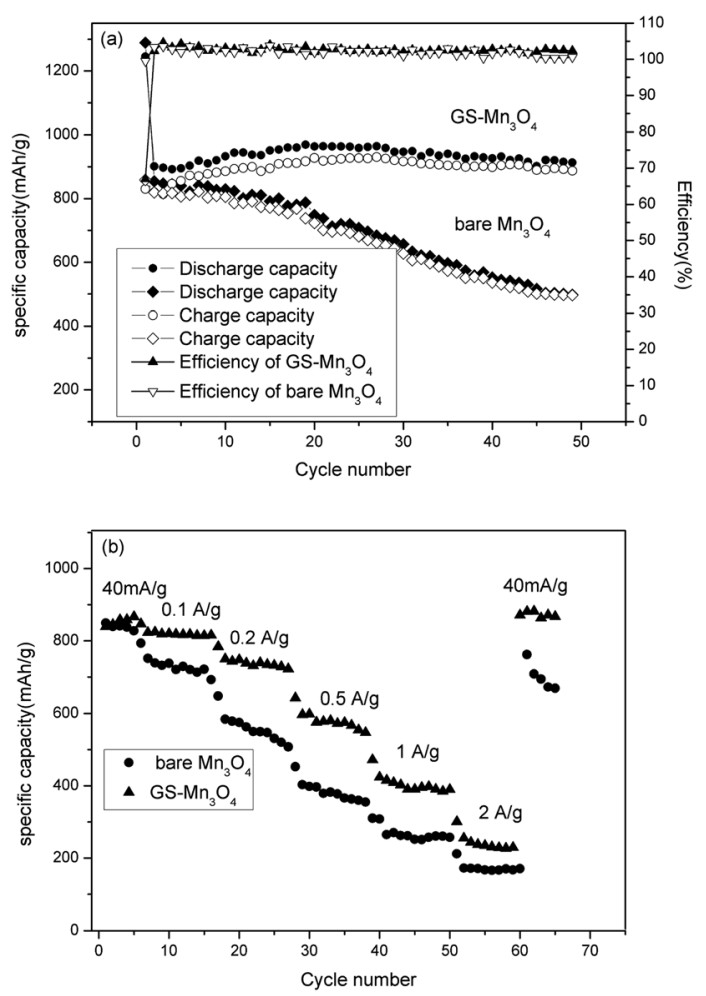

Fig. 5 (a) Cycling performance of the GS- $\mathrm{Mn}_{3} \mathrm{O}_{4}$ nanocomposite and bare $\mathrm{Mn}_{3} \mathrm{O}_{4}$ at a current density of $40 \mathrm{~mA} \mathrm{~g}^{-1}$; (b) rate performance of GS- $\mathrm{Mn}_{3} \mathrm{O}_{4}$ nanocomposite and bare $\mathrm{Mn}_{3} \mathrm{O}_{4}$ particles at different current densities. 
higher than that before at $40 \mathrm{~mA} \mathrm{~g}^{-1}$, indicating excellent cycling stability.

From the comparison between the GS- $\mathrm{Mn}_{3} \mathrm{O}_{4}$ nanocomposite and the bare $\mathrm{Mn}_{3} \mathrm{O}_{4}$, we can conclude that the excellent electrochemical performance, including high reversible capacity, improved cycle stability, and high rate performance, of the GS$\mathrm{Mn}_{3} \mathrm{O}_{4}$ nanocomposite can be ascribed to the following factors: first, the high conductivity of the graphene sheets plays a significant role, as the GS acts as an ionic and electronic transport medium in the electrode during the charge/discharge processes; secondly, the decreased particle size of $\mathrm{Mn}_{3} \mathrm{O}_{4}$ particles in the composite material and the intimate interaction between the flexible GS and the $\mathrm{Mn}_{3} \mathrm{O}_{4}$ particles directly fabricated on the surface of the GS not only effectively confines the growth of the $\mathrm{Mn}_{3} \mathrm{O}_{4}$ particles, but also affords an elastic buffer to alleviate the agglomeration and cracking of $\mathrm{Mn}_{3} \mathrm{O}_{4}$ particles that is associated with the volume expansion during cycling, thus maintaining the structural integrity and avoiding rapid loss of electrode capacity, which is beneficial for cycling stability, and also enables $\mathrm{Li}$ ion transport from $\mathrm{Mn}_{3} \mathrm{O}_{4}$ particles to be more effective and rapid. Hence, such a nanocomposite could deliver an enhanced electrochemical performance as an anode material in rechargeable LIBs.

To gain further understanding of the relationship between the graphene sheets and the bare $\mathrm{Mn}_{3} \mathrm{O}_{4}$ nanoparticles, we conducted a series of calculations (see computational details in the ESI $\dagger$ ) to study the charge transfer from the graphene layer to $\mathrm{Mn}_{3} \mathrm{O}_{4}$. Fig. 6(a) exhibits a top view of the fully relaxed GS$\mathrm{Mn}_{3} \mathrm{O}_{4}(001)$ nanocomposite. The equilibrium distance between

(a)

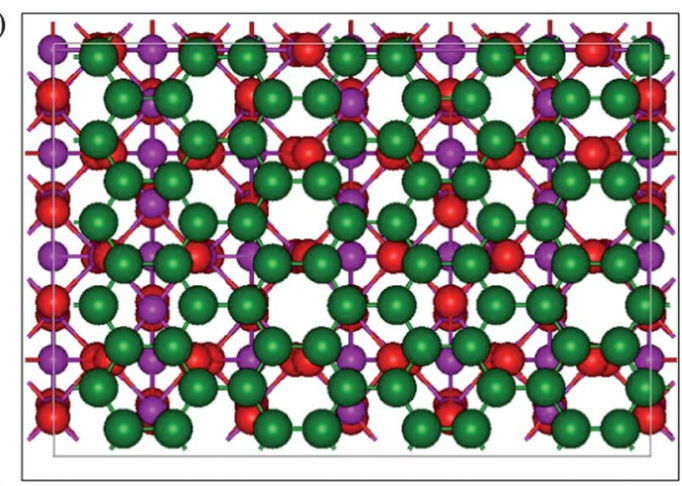

(b)

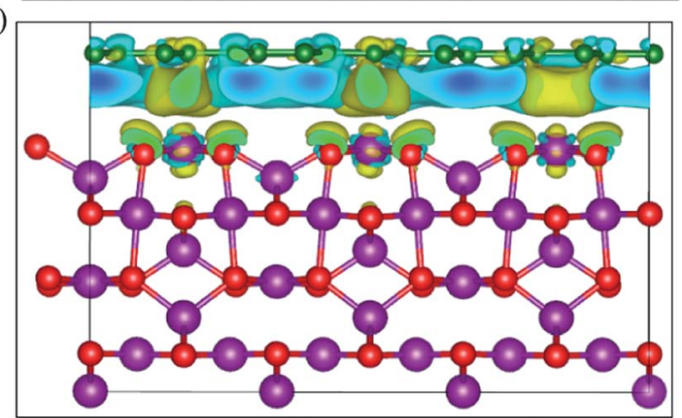

Fig. 6 (a) Top view of the optimized GS- $\mathrm{Mn}_{3} \mathrm{O}_{4}(001)$ and (b) side view of a three-dimensional charge density difference plot for the interface between a graphene sheet and a $\mathrm{Mn}_{3} \mathrm{O}_{4}(001)$ surface. Magenta, red, and green balls represent $\mathrm{Mn}, \mathrm{O}$, and $\mathrm{C}$ atoms, respectively. Cyan and yellow isosurfaces represent charge depletion and accumulation in the space, with an isovalue of $0.015 \mathrm{e}^{-3}$. the graphene layer and the top of the $\mathrm{Mn}_{3} \mathrm{O}_{4}(001)$ surface is calculated to be $2.91 \AA$. The interface adhesion energy was obtained according to the following equation:

$$
E_{\text {ad }}=E_{\text {comb }}-E_{\text {graphene }}-E_{\mathrm{Mn}_{3} \mathrm{O}_{4}(001)}
$$

where $E_{\text {comb }}, E_{\text {graphene, }}$ and $E_{\mathrm{Mn}_{3} \mathrm{O}_{4}(001)}$ represent the total energy of the relaxed GS- $\mathrm{Mn}_{3} \mathrm{O}_{4}$ nanocomposite, the pure graphene sheet, and the clean $\mathrm{Mn}_{3} \mathrm{O}_{4}(001)$ slab, respectively. The interface binding energy is as high as $-4.45 \mathrm{eV}$ for the whole model interface, which indicates very high stability. To characterize the electron coupling at the $\mathrm{GS}-\mathrm{Mn}_{3} \mathrm{O}_{4}$ interface, three-dimensional charge density difference plots were calculated by subtracting the electronic charge of the hybrid GS- $\mathrm{Mn}_{3} \mathrm{O}_{4}$ nanocomposite from those of the separate graphene layer and the $\mathrm{Mn}_{3} \mathrm{O}_{4}(001)$ surface as shown in Fig. 6(b). Clearly, there is significant charge transfer from the graphene layer to the $\mathrm{Mn}_{3} \mathrm{O}_{4}(001)$ surface in the ground electronic state, which considerably enhances the electronic conductivity of the whole nanocomposite. The Nyquist plots also give further evidence that the charge transfer resistance has decreased in the $\mathrm{GS}-\mathrm{Mn}_{3} \mathrm{O}_{4}$ nanocomposite, as shown in Fig. $\mathrm{S} 3 \uparrow$. Accordingly, this can also further elucidate the intrinsic reason why the electrochemical performance of the GS- $\mathrm{Mn}_{3} \mathrm{O}_{4}$ nanocomposite enormously surpasses that of the bare $\mathrm{Mn}_{3} \mathrm{O}_{4}$ nanoparticle sample, which is virtually an insulator.

\section{Conclusions}

We successfully synthesized a $\mathrm{Mn}_{3} \mathrm{O}_{4}$-embedded graphene sheet nanocomposite that was directly prepared from GO via a facile, effective, energy-saving, and scalable microwave hydrothermal technique. The $\mathrm{Mn}_{3} \mathrm{O}_{4}$ particles in the nanocomposite, directly growing on the surface of the graphene sheets, interact with each other intimately, so that the nanocomposite exhibits better electrochemical properties than the bare sample, including a high reversible specific capacity of more than $900 \mathrm{~mA} \mathrm{~h} \mathrm{~g}^{-1}$ at $40 \mathrm{~mA} \mathrm{~g}^{-1}$. Even at a high current density of $1000 \mathrm{~mA} \mathrm{~g}^{-1}$, this material still can achieve an acceptable capacity of $400 \mathrm{~mA} \mathrm{~h} \mathrm{~g}^{-1}$. In addition, the most attractive property of this nanocomposite should be its extraordinary cycling stability, with no decay in capacity for up to 50 cycles. The theoretical calculations further give evidence that there is charge transfer between the graphene and the $\mathrm{Mn}_{3} \mathrm{O}_{4}$ nanoparticles. The GS- $\mathrm{Mn}_{3} \mathrm{O}_{4}$ nanocomposite fabricated by such an energy-saving microwave hydrothermal technique could be considered as a candidate anode material in future larger scale energy storage devices.

\section{Acknowledgements}

This work was funded by an Australian Research Council (ARC) Discovery Project (DP1094261). The authors would like to thank Dr Tania Silver at the University of Wollongong for critical reading of the manuscript and $\mathrm{Mr}$ Darren Attard for his great contribution.

\section{Notes and references}

1 T. Yamashita and A. Vannice, J. Catal., 1996, 161, 254.

2 H. Einaga and S. Futamura, J. Catal., 2004, 227, 304. 
3 M. Johns, P. Landon, T. Alderson and G. J. Hutchings, Chem Commun., 2001, 2454.

4 (a) N. Sakai, Y. Ebina, K. Takada and T. Sasaki, J. Electrochem. Soc., 2005, 12, E384; (b) W. Xao, J. S. Chen and X. W. (David) Lou, CrystEngComm, 2011, 13, 5685.

5 C. C. Hu, Y. T. Wu and K. H. Chang, Chem. Mater., 2008, 20, 2890

6 D. Pasero, N. Reeves and A. R. West, J. Power Sources, 2005, 141, 156

7 A. A. Balandin, S. Ghosh, W. Z. Bao, I. Calizo, D. Teweldebrhan, F. Miao and C. N. Lau, Nano Lett., 2008, 8, 902.

8 Z. S. Wu, W. C. Ren, L. B. Gao, J. P. Zhao, Z. P. Chen, B. L. Liu, D. M. Tang, B. Yu, C. B. Jiang and H. M. Cheng, ACS Nano, 2009, 3, 411-417.

9 K. I. Bolotin, K. J. Sikes, Z. Jiang, M. Klima, G. Fudenberg, J. Hone, P. Kim and H. L. Stormer, Solid State Commun., 2008, 146, 351.

10 S. V. Morozov, K. S. Novoselov, M. I. Katsnelson, F. Schedin, D. C. Elias, J. A. Jaszczak and A. K. Geim, Phys. Rev. Lett., 2008, 100, 016602.

11 D. A. Dikin, S. Stankovich, E. J. Zimney, R. D. Piner, G. H. B. Dommett, G. Evmenenko, S. T. Nguyen and R. S. Ruoff, Nature, 2007, 448, 457.

12 C. Lee, X. D. Wei, J. W. Kysar and J. Hone, Science, 2008, 321, 385 13 S. M. Paek, E. J. Yoo and I. Honma, Nano Lett., 2009, 9, 72.

14 D. Wang, D. Choi, J. Li, Z. Yang, Z. Nie, R. Kou, D. Hu, C. Wang, L. V. Saraf, J. Zhang, I. A. Aksay and J. Liu, ACS Nano, 2009, 3, 90715; H. Wang, J. T. Robinson, G. Diankov and H. Dai, J. Am. Chem. Soc., 2010, 132, 3270.

15 G. D. Du, K. H. Seng, Z. P. Guo, J. Liu, W. X. Li, D. Z. Jia, C. Cook, Z. W. Liu and H. K. Liu, RSC Adv., 2011, 1, 690.

16 Y. C. Si and E. T. Samulski, Chem. Mater., 2008, 20, 6792

17 C. Xu, X. Wang and J. W. Zhu, J. Phys. Chem. C, 2008, 112, 19841

18 R. Muszynski, B. Seger and P. V. Kamat, J. Phys. Chem. C, 2008, 112, 5263.

19 N. A. Luechinger, E. K. Athanassiou and W. J. Stark, Nanotechnology, 2008, 19, 445201.

20 H. K. He and C. Gao, ACS Appl. Mater. Interfaces, 2010, 2, 320.

21 C. Xu, X. Wang, J. W. Zhu, X. J. Yang and L. Lu, J. Mater. Chem., $2008, \mathbf{1 8}, 5625$.
22 Z. S. Wu, W. C. Ren, L. Wen, L. B. Gao, J. P. Zhao, Z. P. Chen, G. M. Zhou, F. Li and H. M. Cheng, ACS Nano, 2010, 4, 3187.

23 X. Y. Yang, X. Y. Zhang, Y. F. Ma, Y. Huang, Y. S. Wang and Y. S. Chen, J. Mater. Chem., 2009, 19, 2710.

24 G. Williams, B. Seger and P. V. Kamat, ACS Nano, 2008, 2, 1487.

25 H. L. Wang, L. F. Cui, Y. Yang, H. S. Casalongue, J. T. Robinson, Y. Y. Liang, Y. Cui and H. J. Dai, J. Am. Chem. Soc., 2010, 132, 13978.

$26 \mathrm{Y}$. Hu, C. Liu, Y. Zhang, N. Ren and Y. Tang, Microporous Mesoporous Mater., 2009, 119, 306.

27 M. L. Dos Santos, R. C. Lima, C. Riccardi, R. Tranquilin, P. Bueno, J. Varela and E. Longo, Mater. Lett., 2008, 62, 4509.

28 X. H. Zhu, J. Y. Wang, Z. H. Zhang, J. M. Zhu, S. H. Zhou, Z. G. Liu and N. B. Ming, J. Am. Ceram. Soc., 2008, 91, 2683.

29 K. H. Seng, Z. P. Guo, Z. X. Chen and H. K. Liu, Adv. Sci. Lett., $2011,4,18$.

30 B. J. Li, H. Q. Cao, J. Shao, M. Z. Qu and J. H. Warner, J. Mater. Chem., 2011, 21, 5069.

31 T. Cassagneau, J. H. Fendler, S. A. Johnson and T. E. Mallouk, $A d v$. Mater., 2000, 12, 1363.

32 Y. G. Wang and H. S. Zhou, Energy Environ. Sci., 2011, 4, 1704.

33 A. Gupta, G. Chen, P. Joshi, S. Tadigadapa and P. C. Eklud, Nano Lett., 2006, 6, 2667-2673.

34 M. C. Bernard, A. Hugot-Le Goff, B. V. Thi and S. Cordoba de Torresi, J. Electrochem. Soc., 1993, 140, 3065.

35 C. M. Julien, M. Massot and C. Poinsignon, Spectrochim. Acta, Part A, 2004, 60, 689 .

36 P. Poizot, S. Laruelle, S. Grugeon, L. Dupont and J. M. Tarascon, Nature, 2000, 407, 496.

37 D. Pasero, N. Reeves and A. R. West, J. Power Sources, 2005, 141, 156.

38 S. Grugeon, S. Laruelle, L. Dupont and J. M. Tarascon, Solid State Sci., 2003, 5, 895 .

39 S. Laruelle, S. Grugeon, P. Poizot, M. Dolle, L. Dupont and J. M. Tarascon, J. Electrochem. Soc., 2002, 149, A627.

40 J. S. Do and C. H. Weng, J. Power Sources, 2005, 146, 482. 